\title{
A course on endovascular training for resuscitative endovascular balloon occlusion of the aorta: a pilot study for residents and specialists
}

\author{
Ye Rim Chang ${ }^{1, *}$, Chan Yong Park ${ }^{2, *}$, Dong Hun Kim ${ }^{1}$, Dae Sung $\mathrm{Ma}^{3}$, Sung Wook Chang \\ ${ }^{1}$ Department of Trauma Surgery, Trauma Center, Dankook University Hospital, Cheonan, Korea \\ ${ }^{2}$ Department of Trauma Surgery, Wonkwang University Hospital, Iksan, Korea \\ ${ }^{3}$ Department of Thoracic and Cardiovascular Surgery, Trauma Center, Dankook University Hospital, Cheonan, Korea
}

\begin{abstract}
Purpose: Resuscitative endovascular balloon occlusion of the aorta (REBOA) has emerged as a salvage technique changing the paradigm in the management of noncompressible torso hemorrhage. However, training for the REBOA procedure is rarely performed. The endovascular training for REBOA (ET-REBOA) course was conducted to develop the endovascular skills of participants.

Methods: Sixteen residents and 12 specialists participated in this educational course. All participants were provided with precourse learning materials. The ET-REBOA course consisted of 2 sections; an ultrasound-guided sheath insertion on the puncture model, and a balloon manipulation on the vascular circuit model. A 13-item procedure checklist and the time required to perform the procedure were examined. Pre/post self-reported confidence score and course satisfaction questionnaire were obtained.

Results: Twenty-eight participants performed the 56 REBOA procedures. On the first attempt, the median total time for REBOA from ultrasound-guided vascular access to balloon inflation was 1,139 \pm 250 seconds in the resident group and $828 \pm 280$ seconds in the specialist group. The median shortened time for completion was 273 seconds and 290 seconds respectively. A significant decrease in procedure task time was observed between first and second attempts in the resident group $(P=0.016)$, specialist group $(P=0.004)$, and in total among all participants $(P<0.001)$.

Conclusion: The ET-REBOA course significantly decreased the time taken to perform the REBOA procedure with high satisfaction of the participants. The course could be an effective curriculum for the development of endovascular skills for performing REBOA.
\end{abstract}

[Ann Surg Treat Res 2020;99(6):362-369]

Key Words: Aorta, Balloon occlusion, Education, Resuscitation, Trauma

\section{INTRODUCTION}

Noncompressible torso hemorrhage (NCTH), which is caused by abdominopelvic and thoracic injuries, is still the primary cause of preventable death in trauma [1,2]. To improve the survival of patients with $\mathrm{NCTH}$, early and effective resuscitation with hemorrhage control is mandatory. In an effort to decrease bleeding below the clamped site while maintaining cerebral and
Received October 27, 2020, Revised November 10, 2020,

Accepted November 12, 2020

\section{Corresponding Author: Sung Wook Chang}

Department of Thoracic and Cardiovascular Surgery, Trauma Center, Dankook University Hospital, 201 Manghyang-ro, Dongnam-gu, Cheonan 31116, Korea

Tel: +82-41-550-7119, Fax: +82-41-550-0039

E-mail: changsw3@naver.com

ORCID: https://orcid.org/0000-0002-2689-3068
* Ye Rim Chang and Chan Yong Park contributed equally to this study as co-first authors.

- The results of this study were presented at the 2 nd Endovascular Resuscitation and Trauma Management round table symposium in June 2018 in Örebro, Sweden.

Copyright (C) 2020, the Korean Surgical Society

(c) Annals of Surgical Treatment and Research is an Open Access Journal. All articles are distributed under the terms of the Creative Commons Attribution NonCommercial License (http://creativecommons.org/licenses/by-nc/4.0/) which permits unrestricted non-commercial use, distribution, and reproduction in any medium, provided the original work is properly cited. 
coronary perfusion, resuscitative thoracotomy (RT) [3] followed by aortic cross clamp (ACC) can be performed in moribund patients as a damage control surgery. However, RT remains associated with high morbidity and mortality [3,4], which acts as a burden against performing the procedure.

Recently, resuscitative endovascular balloon occlusion of the aorta (REBOA) has been gaining acceptance as an alternative to RT followed by ACC in the management of select patients with NCTH [5-8]. The paradigm is shifting with respect to the management of hemorrhagic shock from abdominopelvic injury since REBOA provides the physiologic benefit of temporary aortic occlusion without the burden of thoracotomy [9]. However, the REBOA procedure remains limited and is regarded as difficult because of the absence of knowledge, experience,

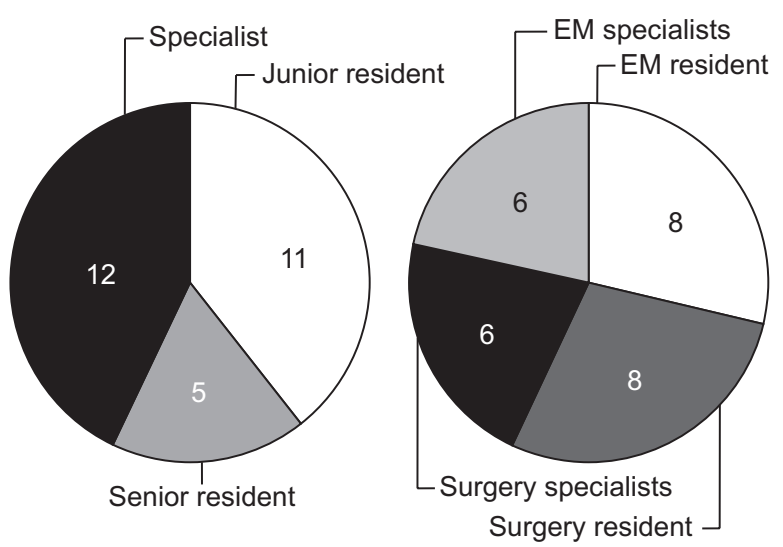

Fig. 1. Participants of study. Eleven junior residents, 5 senior residents, and 12 specialists participated in the course. Surgeons and emergency physicians comprised $50 \%$, respectively. EM, emergency medicine. and proper training among physicians. The purpose of this study was to introduce the endovascular training for REBOA (ET-REBOA) course and to evaluate its effectiveness.

\section{METHODS}

Eleven 1st- and 2nd-year junior residents, five 3rd- and 4thyear senior residents, and 12 specialists (fellows and staffs) from Dankook University Hospital with no prior experience in performing the REBOA procedure participated in this educational course. All specialists were board-certified and included; 6 emergency physicians, 4 general surgeons, 1 cardiothoracic surgeon, and 1 neurosurgeon who took calls in the trauma resuscitation unit at the level I trauma center in Dankook University Hospital (Fig. 1). The course was conducted by 4 full-time trauma faculty members (1 cardiothoracic surgeon and 3 general surgeons) from Dankook University Hospital who had experience with the REBOA procedure as well as the educational model. Each trainee was matched to 2 instructors at a time.

All participants were provided with precourse learning materials 1 week prior to the course. These lecture notes provided an introduction to the aortic zone, role, indication, and sequences of REBOA. The demonstration videos (Fig. 2) included instructions on how to perform the preparations (sheath, wire, and balloon catheter) and procedures (ultrasoundguided vascular access, balloon insertion, and balloon inflation in accordance to the target level). On the day of training, 60 minutes of lecture plus discussion was provided (Table 1).

The hands-on course consisted of 2 sections; (1) ultrasoundguided sheath insertion and (2) balloon manipulation.
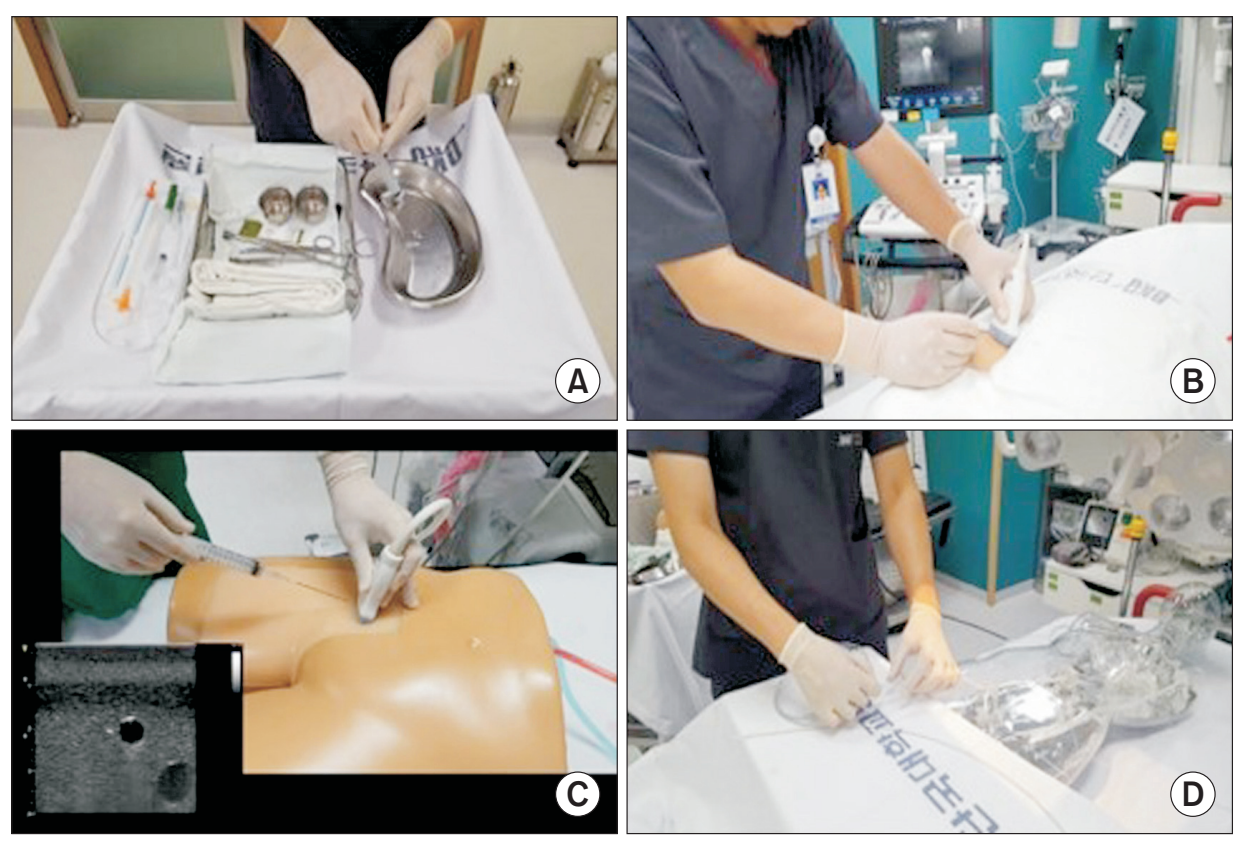

Fig. 2. Precourse learning materials. Demonstration videos showing still frames of how to do the preparations $(A)$, ultrasoundguided vascular access $(B, C)$, and balloon insertion (D). 
Ultrasound-guided sheath insertion was performed on the lower torso model (Blue Phantom, femoral vascular access lower torso ultrasound model; CAE Healthcare, Dallas, TX, USA) using 7 Fr Radiofocus Introducer II (Terumo, Tokyo, Japan). This model is a manikin with femoral vascular access replacement tissue, which allows for realistic ultrasound imaging to guide needle and catheter insertions into the pulsated femoral artery distinguished from vein. The balloon was inserted and inflated on the vascular circuit model EVE (EndoVascular Evaluator, BR Biomedicals Pvt. Ltd., New Delhi, India) using 7-Fr RESCUE Balloon (Tokai Medical Products, Kasugai, Japan). This model is made of special silicone that recreates the elasticity and friction of human vasculature, simulating the sensation and behavior

Table 1. Programs of the course

\begin{tabular}{ll}
\hline 1. Lecture & 1) Concepts for REBOA \\
2) Vascular access \\
3) Wire technique and balloon management \\
4) REBOA kit \\
5) Pelvic bleeding and REBOA \\
6) Torso bleeding and REBOA \\
7) Model simulation \\
- Sheath preparation and insertion \\
- Ultrasound-guided vascular access \\
- Wire and balloon preparation \\
- REBOA catheter insertion \\
8) Discussion \\
2. Hands-on course \\
1) Ultrasound-guided sheath insertion \\
- Zalloon manipulation \\
- Zone Ill placement
\end{tabular}

REBOA, resuscitative endovascular balloon occlusion of the aorta. of catheter manipulation during an endovascular procedure. Artery pulsation can be simulated using a pulsed flow pump, the pressure of which can be changed by aortic occlusion. It also provides compatibility with a wide range of X-ray imaging techniques.

Each section was repeated twice, and the time taken to complete each procedure was recorded to evaluate improvements in the skill of the participants. Participants performed both zone I and III REBOA alternately using 2 case scenarios; (1) a moribund patient with a massive hemoperitoneum confirmed by focused assessment with sonography for trauma (zone I) and (2) an unstable pelvic bone fracture by pelvic X-ray (zone III). Portable X-ray (Fig. 3) was taken to check the position of the guidewire and balloon during the course.

The procedure checklist contained a total of 13 items (Table 2). Participants received a "fail" if they (1) did not successfully access a femoral artery using the ultrasound-guided technique, (2) inflated the REBOA balloon during preparation, 3) did not change from the soft guidewire to the stiff wire before balloon inflation, or 4) inflated the balloon before checking the balloon position. Residents who failed their first attempt were given additional opportunities to acquire the correct skills without a time limit. Instructors gave tips and feedback to the participants immediately after the first attempt according to the checklist.

Participants rated their confidence in performing REBOA immediately before and after the course on a scale from 1 (strongly disagree) to 10 (strongly agree). The post-assessment contained the same questions as the pre-assessment. After completing the course, participants also completed an 11-
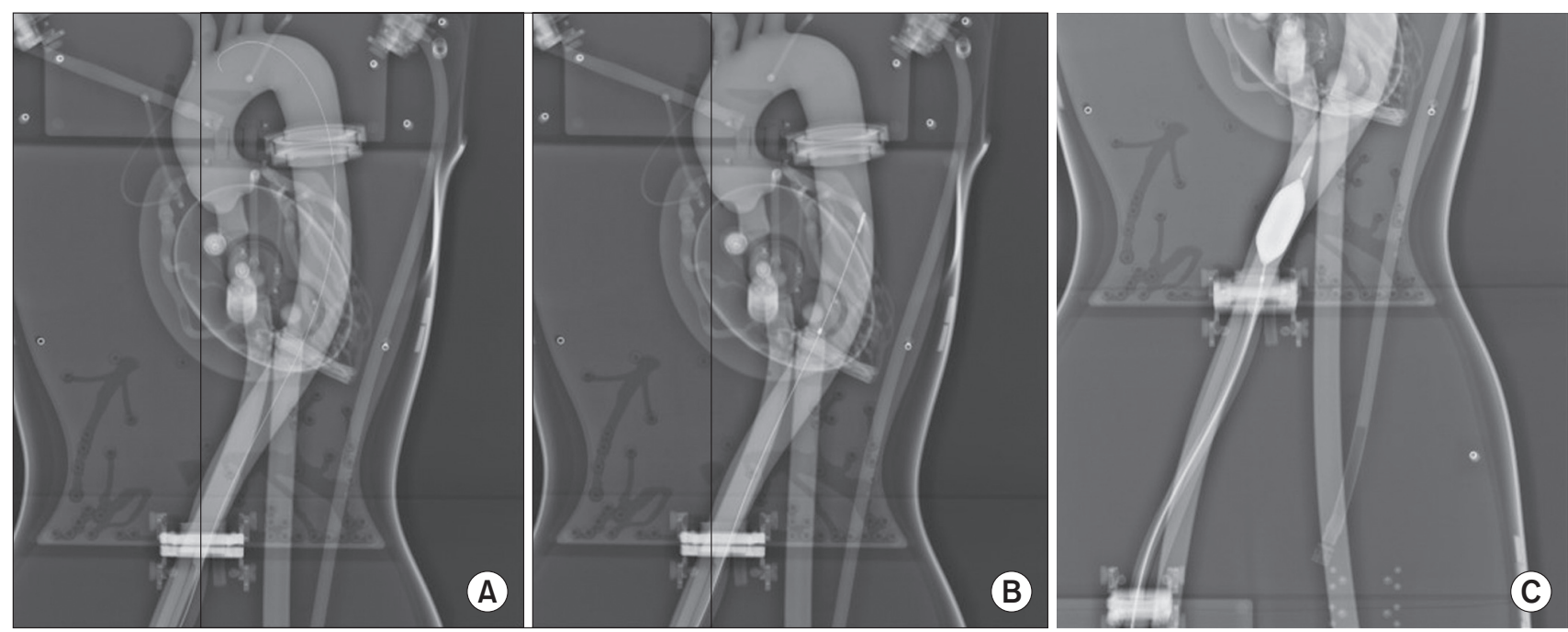

Fig. 3. X-ray of EVE (EndoVascular Evaluator, BR Biomedicals Pvt. Ltd., New Delhi, India) showing the resuscitative endovascular balloon occlusion of the aorta (REBOA) catheter. X-ray was taken during the balloon manipulation to check the position of a guidewire and a balloon before inflation. (A) Guidewire in the aorta of EVE, (B) REBOA catheter before inflation, and (C) REBOA balloon in the aorta of EVE. 
item course satisfaction questionnaire, which also employed a 10-point scale.

For the course analysis, continuous variables were compared using paired t-tests, and P-values of $<0.05$ were considered statistically significant. All statistical analyses were performed

Table 2. Procedure checklist

\begin{tabular}{|c|c|c|}
\hline Item & Not done Incorrect & Correct \\
\hline \multicolumn{3}{|l|}{ Sheath insertion } \\
\hline Sheath priming & & V \\
\hline Ultrasound-guided puncture & & V \\
\hline Sheath guidewire insertion & & $\mathrm{V}$ \\
\hline Sheath insertion ${ }^{\text {a) }}$ & & V \\
\hline \multicolumn{3}{|l|}{ Balloon insertion } \\
\hline Guidewire priming & & $\mathrm{V}$ \\
\hline Balloon priming & & V \\
\hline Balloon test ${ }^{\text {b) }}$ & V & \\
\hline Guidewire position check & & V \\
\hline $\begin{array}{l}\text { Balloon position measurement } \\
\text { using body landmarks }\end{array}$ & & V \\
\hline Balloon insertion & & V \\
\hline $\begin{array}{l}\text { Stiff wire insertion before } \\
\text { inflation }{ }^{\text {a) }}\end{array}$ & & V \\
\hline $\begin{array}{l}\text { Balloon position check before } \\
\text { inflation }^{\text {a) }}\end{array}$ & & V \\
\hline Final balloon position & & V \\
\hline
\end{tabular}

a) Participants received a "fail" grade if they did not complete the item. "Participants received a "fail" grade if they inflated the balloon during preparation.

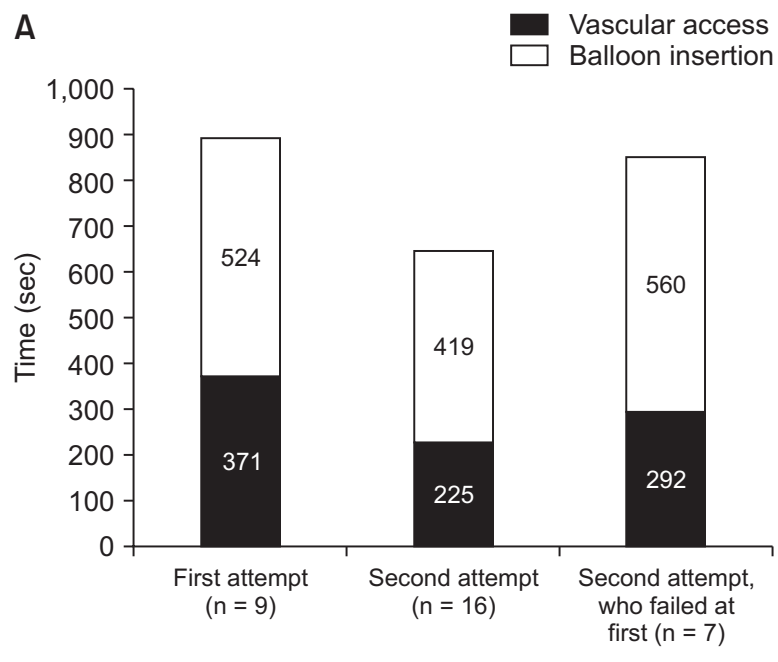

\begin{tabular}{|c|c|c|c|}
\hline & $\begin{array}{c}\text { Vascular } \\
\text { access }\end{array}$ & $\begin{array}{c}\text { Balloon } \\
\text { insertion }\end{array}$ & $\begin{array}{c}\text { Total } \\
\text { time }\end{array}$ \\
\hline $\begin{array}{c}\text { Shortened time } \\
\text { (median, sec) }\end{array}$ & 75.0 & 198.0 & 273.0 \\
\hline
\end{tabular}

using PASW Statistics ver. 19 (IBM Corp., Armonk, NY, USA). This study was approved by the Institutional Review Board of the Dankook University Hospital (No. 201910001) and agreement was obtained from the participants.

\section{RESULTS}

A total of 56 REBOA procedures were performed in the ETREBOA course by 28 participants. No one in the specialist group failed the procedure on their first attempt. However, 7 of the 16 residents ( 5 junior residents and 2 senior residents) failed their first attempt. According to the procedure checklists there were 10 reasons for failure; no sheath priming $(\mathrm{n}=1)$, no guidewire priming $(n=1)$, no balloon priming $(n=2)$, balloon test before insertion $(\mathrm{n}=1)$, balloon inflation before insertion of a stiff wire $(n=2)$, and balloon inflation before checking the balloon position $(\mathrm{n}=3)$.

On the first attempt, the median time from ultrasoundguided vascular access to balloon inflation was 1,139 \pm 250 seconds (range, 513-1,329 seconds) in the resident group and $828 \pm 280$ seconds (range, 478-1,384 seconds) in the specialist group. For residents and specialists who performed the REBOA procedures successfully in both attempts, the time for completion of the procedure was shorter at the second attempt compared to that at the first attempt, with the median shortened time for completion being 273 seconds in the resident group and 290 seconds in the specialist group (Fig. 4). A significant decrease in procedure task time was

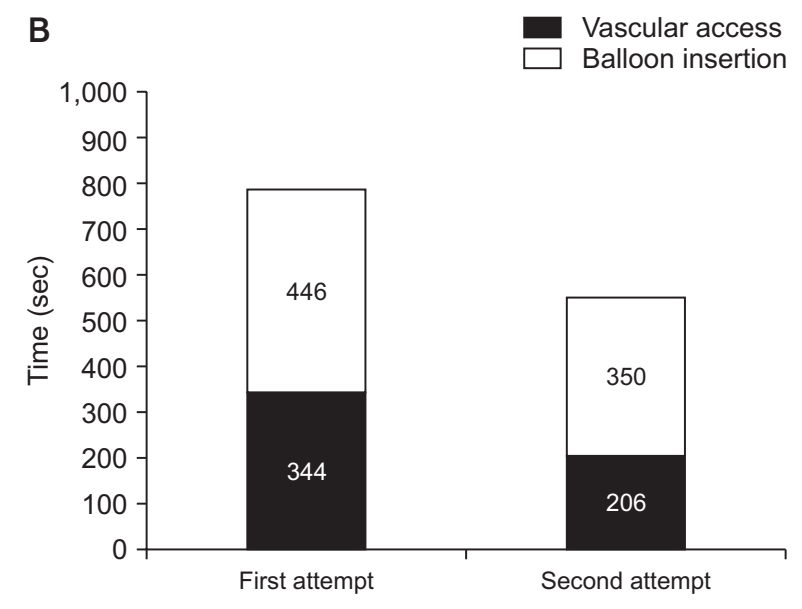

\begin{tabular}{|c|c|c|c|}
\hline & $\begin{array}{c}\text { Vascular } \\
\text { access }\end{array}$ & $\begin{array}{c}\text { Balloon } \\
\text { insertion }\end{array}$ & $\begin{array}{c}\text { Total } \\
\text { time }\end{array}$ \\
\hline $\begin{array}{c}\text { Shortened time } \\
\text { (median, sec) }\end{array}$ & 116.0 & 97.0 & 289.5 \\
\hline
\end{tabular}

Fig. 4. Changes in time for the procedure of the resident group $(A, n=16)$ and the specialist group $(B, n=12)$. The median time for vascular access and balloon insertion was markedly shortened at the second attempt compared to the first attempt both in residents and specialist groups. 
observed between first and second attempts in the resident group $(P=0.016)$, specialist group $(P=0.004)$, and in total among all participants $(\mathrm{P}<0.001)$ (Table 3 ). With regards to each procedure, time for balloon insertion decreased more in the resident group (198 seconds), while time for ultrasoundguided vascular access decreased more in the specialist group (116 seconds). The residents who failed their first attempt all successfully completed procedure during their second attempt, with a median time of 852 seconds (Fig. 4). Line plots of the time taken to complete procedures for each participant show a dramatic decrease between the first and second attempts, except for one participant from the resident group (Fig. 5).

Previous experience with ultrasound-guided vascular access or femoral vessel catheterization did not make a difference in the time taken to complete the procedure (Table 4). The length of time required for balloon placement in zones I and III also was not different among participants.

Self-reported confidence scores increased most for the item "I

Table 3. Time to complete the procedure among participants

\begin{tabular}{|c|c|c|c|}
\hline \multirow[b]{2}{*}{ Procedure } & \multicolumn{2}{|c|}{ Time (sec), mean } & \multirow[b]{2}{*}{ P-value } \\
\hline & $\begin{array}{c}\text { First } \\
\text { attempt }\end{array}$ & $\begin{array}{l}\text { Second } \\
\text { attempt }\end{array}$ & \\
\hline \multicolumn{4}{|c|}{ Residents who successfully completed the procedure $(n=9)$} \\
\hline Vascular access & 443.0 & 287.4 & 0.124 \\
\hline Balloon insertion & 579.2 & 423.9 & 0.048 \\
\hline Total & $1,022.2$ & 711.3 & 0.016 \\
\hline \multicolumn{4}{|l|}{ Specialists $(\mathrm{n}=12)$} \\
\hline Vascular access & 438.2 & 225.2 & 0.011 \\
\hline Balloon insertion & 433.1 & 340.5 & 0.013 \\
\hline Total & 871.3 & 565.7 & 0.004 \\
\hline \multicolumn{4}{|c|}{ All participants who successfully completed the procedure $(n=21)$} \\
\hline Vascular access & 440.2 & 251.9 & 0.002 \\
\hline Balloon insertion & 495.7 & 376.2 & 0.005 \\
\hline Total & 935.9 & 628.1 & $<0.001$ \\
\hline
\end{tabular}

know how to inflate/deflate a balloon correctly," which had the lowest score before the course. The item "I know which vessel to puncture" ranked highest in the postcourse assessment (Table 5). On the course satisfaction questionnaire, "I would recommend the ET-REBOA course to my colleagues" was the item with the highest score while "I feel ready to do REBOA in the clinical practice" was the item with the lowest (Table 6).

\section{DISCUSSION}

The time and place where REBOA has the greatest potential to improve survival after trauma are at patient presentation to the resuscitation area or shortly thereafter [10]. Although it is essential to attain proficiency before performing the procedure at this critical juncture, most physicians have limited exposure to endovascular techniques. There are limited reports on endovascular training $[9,10]$ even though REBOA has been
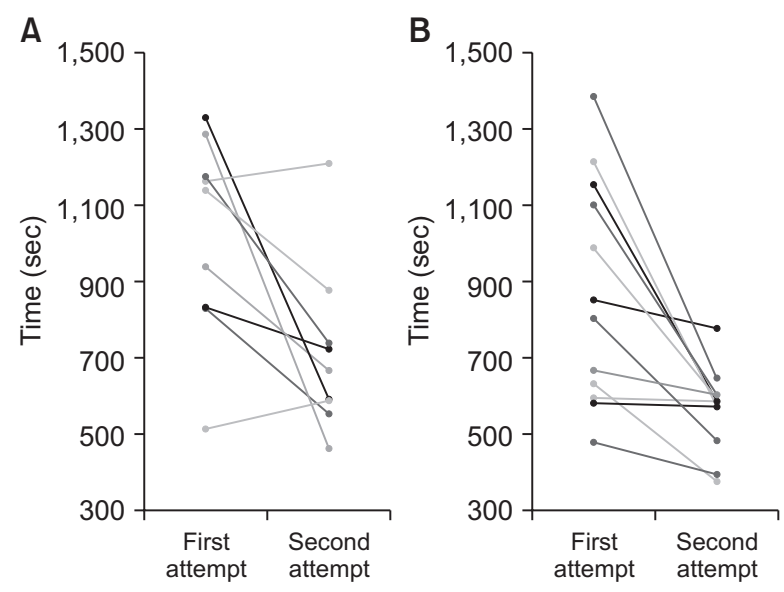

Fig. 5. Line plots of time for the procedure of the resident group $(A, n=16)$ and the specialist group $(B, n=12)$. Each participant showed a dramatic decrease from first to second attempt except 1 participant from the resident group.

Table 4. Time to complete the procedure according to previous experience

\begin{tabular}{|c|c|c|c|c|c|c|c|c|}
\hline \multirow{2}{*}{ Participant } & \multicolumn{4}{|c|}{ First attempt (sec), mean ${ }^{\mathrm{a})}$} & \multicolumn{4}{|c|}{ Second attempt (sec), mean } \\
\hline & Vascular access & Balloon insertion & Total & P-value & Vascular access & Balloon insertion & Total & P-value \\
\hline \multicolumn{4}{|c|}{ I have seen REBOA before } & 0.084 & & & & 0.861 \\
\hline Yes $(n=23)$ & 411.0 & 471.2 & 882.2 & & 265.6 & 428.9 & 694.5 & \\
\hline No $(\mathrm{n}=5)$ & 564.5 & 600.0 & $1,164.5$ & & 394.2 & 336.6 & 730.8 & \\
\hline \multicolumn{4}{|c|}{ I have prior experience with ultrasound-guided vascular access } & 0.984 & & & & 0.314 \\
\hline Yes $(n=18)$ & 468.1 & 468.8 & 936.9 & & 259.6 & 400.8 & 660.4 & \\
\hline No $(n=10)$ & 384.6 & 549.6 & 934.1 & & 340.8 & 433.4 & 774.2 & \\
\hline \multicolumn{4}{|c|}{ I have prior experience with other endovascular procedures ${ }^{\mathrm{b})}$} & 0.501 & & & & 0.070 \\
\hline Yes $(n=23)$ & 418.6 & 487.3 & 905.9 & & 295.6 & 436.6 & 732.1 & \\
\hline No $(\mathrm{n}=5)$ & 509.6 & 522.6 & $1,032.2$ & & 256.4 & 301.4 & 557.8 & \\
\hline
\end{tabular}

REBOA, resuscitative endovascular balloon occlusion of the aorta.

${ }^{a}$ Failed residents were excluded from this analysis. ${ }^{\text {b) }}$ Vascular access via Seldinger approach into femoral artery/vein. 
Table 5. Self-reported confidence score (10-point scale)

\begin{tabular}{lccc}
\hline \multicolumn{1}{c}{ Item } & Precourse & Postcourse & Difference \\
\hline I know how to perform ultrasound-guided vascular access. & $5.25 \pm 2.19$ & $8.07 \pm 2.19$ & 2.82 \\
I know which vessel to puncture. & $6.82 \pm 2.97$ & $9.32 \pm 1.19$ & 2.50 \\
I know how to insert a vascular sheath. & $6.36 \pm 2.37$ & $8.64 \pm 1.87$ & 2.29 \\
I know how to insert a guidewire. & $6.50 \pm 2.30$ & $9.04 \pm 1.62$ & 2.54 \\
I know when and how to insert a stiff guidewire. & $4.79 \pm 3.14$ & $9.11 \pm 1.45$ & 4.32 \\
I know how to position a balloon correctly. & $4.64 \pm 3.11$ & $8.68 \pm 1.66$ & 4.04 \\
I know how to inflate/deflate a balloon correctly. & $4.21 \pm 3.04$ & $8.68 \pm 1.70$ & 4.46 \\
\hline
\end{tabular}

Values are presented as mean \pm standard deviation.

Table 6. Postcourse questionnaire (10-point scale)

\begin{tabular}{lc}
\hline \multicolumn{1}{c}{ Item } & Score \\
\hline The prelearning method was satisfactory. & $9.04 \pm 1.48$ \\
Precourse learning material was helpful. & $9.11 \pm 1.50$ \\
The equipment used in the course was suitable for learning. & $8.96 \pm 1.71$ \\
The course offered sufficient time to learn. & $9.29 \pm 1.15$ \\
The level of difficulty of the course was appropriate for me. & $9.14 \pm 1.43$ \\
I gained new knowledge. & $9.68 \pm 0.72$ \\
I learned a new technique. & $9.64 \pm 0.78$ \\
I feel ready to perform REBOA in clinical practice. & $7.93 \pm 2.36$ \\
The course is worthwhile for trauma management. & $9.75 \pm 0.65$ \\
I am pleased that I took the course. & $9.57 \pm 0.79$ \\
I would recommend the ET-REBOA course to my colleagues. & $9.71 \pm 0.71$
\end{tabular}

Values are presented as mean \pm standard deviation.

REBOA, resuscitative endovascular balloon occlusion of the aorta; ET-REBOA, endovascular training for REBOA.

increasingly used worldwide over the past decades [6,11-14].

Several educational courses teach the REBOA procedure; examples include the Endovascular Skills for Trauma and Resuscitative Surgery (ESTARS) course [9] and the Endovascular Resuscitation, Bleeding and Trauma Management (EVTM) hands-on workshop. The ESTARS course is mainly composed of didactics focused on vascular injury including surgical and endovascular techniques, and the EVTM hands-on workshop is concentrated on stormy discussion and the practice of EVTM using a multidisciplinary team approach. The ET-REBOA course places emphasis on understanding and performing the REBOA procedure. Therefore, the ET-REBOA pilot course was rated highly satisfactory (score 9.57) and was highly recommended (score 9.71) by the participants who wanted to learn the REBOA procedure.

There are several differences between this course and other courses. First, the ET-REBOA course adopted a modified form of a flipped learning. Flipped learning is a pedagogical approach where students are introduced to the learning material before class, which positively impacts self-directed learning readiness and engages students more in the content [15]. Precourse learning materials in the form of lecture notes and videos provided one week prior to the course seemed to be satisfactory and helpful, with mean scores of 9.04 and 9.11, respectively, according to the questionnaire. Second, the devices used in the course allowed for realistic ultrasound imaging and provided the sensation of catheter manipulation during an endovascular procedure. A 7-Fr RESCUE Balloon was used to teach basic manipulation of the balloon as well as the difference in sensation between total and partial occlusion. Third, checklists were used to emphasize and imprint steps essential to the success of the REBOA procedure.

In this study, there was a significant decrease in procedure task time between the first and second attempts among participants. Novice trainees also significantly improved their performance after the course. This may suggest that this procedure can be learned and performed regardless of years of training or practice.

Interestingly, previous experience with ultrasound-guided vascular access or other endovascular procedures (vascular access via the Seldinger approach into a femoral artery/vein) did not affect performance measures. This may present the question of whether the model allows for a realistic experience with the REBOA procedure. Although these devices are optimized for endovascular training, gaps between in vivo and ex vivo experience may still exist. The effect of this pilot course 
will be evaluated at a later date by comparing the following clinical outcomes of trauma patients who were managed with REBOA before and after their physicians took this course: procedure-related complications, duration of procedure, and patient outcome.

After this pilot study, there were several updates in the course targeting the traumatologists practicing at trauma center in South Korea. The course was modified to comprise lectures, discussion, and 3 hands-on sessions; 5-Fr sheath insertion, sheath upsizing (5- to 7-Fr sheath), and balloon manipulation. The members from the Group for Resuscitative Endovascular \& Advanced Treatment on Trauma (GREAT) and Korean Association for Research, Procedure and Education on Trauma (KARPET) were trained and joined as course instructors. Three instructors were assigned to each hands-on session, and participants assembled into teams of 3 to 4 , where they took turns playing the role of operator, assistant, and checklist recorder.

In conclusion, the ET-REBOA course significantly decreased the time taken to perform the REBOA procedure with high satisfaction of the participants. The course could be an effective addition to the curriculum for the development of endovascular skills for performing REBOA.

\section{ACKNOWLEDGEMENTS}

The authors appreciate the support received from the Chi Young Lee, the President and C.E.O of Intervention Medical Co., Ltd. for providing 7-Fr Radiofocus Introducer II and 7-Fr RESCUE Balloon.

\section{Conflict of Interest}

No potential conflict of interest relevant to this article was reported.

\section{ORCID iD}

Ye Rim Chang: https://orcid.org/0000-0002-2177-2304

Chan Yong Park: https://orcid.org/0000-0002-5111-3270

Dong Hun Kim: https://orcid.org/0000-0001-6613-6902

Dae Sung Ma: https://orcid.org/0000-0001-7521-3949

Sung Wook Chang: https://orcid.org/0000-0002-2689-3068

\section{Author Contribution \\ Conceptualization: SWC \\ Formal Analysis: YRC \\ Investigation: YRC, DHK, SWC \\ Methodology: YRC, DHK, DSM, CYP, SWC \\ Project Administration: YRC, DHK, DSM, CYP, SWC \\ Writing - Original Draft: YRC, SWC \\ Writing - Review \& Editing: All authors}

\section{REFERENCES}

1. Sim J, Lee J, Lee JC, Heo Y, Wang H, Jung $\mathrm{K}$. Risk factors for mortality of severe trauma based on 3 years' data at a single Korean institution. Ann Surg Treat Res 2015;89:215-9.

2. Andres J, Scott J, Giannoudis PV. Resuscitative endovascular balloon occlusion of the aorta (REBOA): what have we learned? Injury 2016;47:2603-5.

3. Belenkiy SM, Batchinsky AI, Rasmussen TE, Cancio LC. Resuscitative endovascular balloon occlusion of the aorta for hemorrhage control: past, present, and future. J Trauma Acute Care Surg 2015;79(4 Suppl 2):S236-42.

4. Seamon MJ, Haut ER, Van Arendonk K, Barbosa RR, Chiu WC, Dente CJ, et al. An evidence-based approach to patient selection for emergency department thoracotomy: a practice management guideline from the Eastern Association for the Surgery of Trauma. J Trauma Acute Care Surg 2015;79:159-73.

5. Kim DH, Chang SW, Matsumoto J. The utilization of resuscitative endovascular balloon occlusion of the aorta: preparation, technique, and the implementation of a novel approach to stabilizing hemorrhage. J Thorac Dis 2018; 10:5550-9.

6. Sadeghi M, Nilsson KF, Larzon T, Pirouzram A, Toivola A, Skoog P, et al. The use of aortic balloon occlusion in traumatic shock: first report from the ABO trauma registry. Eur J Trauma Emerg Surg 2018;44:491-501.

7. Saito N, Matsumoto H, Yagi T, Hara Y, Hayashida K, Motomura T, et al. Evaluation of the safety and feasibility of resuscitative endovascular balloon occlusion of the aorta. J Trauma Acute Care Surg 2015;78:897-903.

8. Moore LJ, Brenner M, Kozar RA, Pasley J, Wade CE, Baraniuk MS, et al. Implementation of resuscitative endovascular balloon occlusion of the aorta as an alternative to resuscitative thoracotomy for noncompressible truncal hemorrhage. J Trauma Acute Care Surg 2015;79:523-30; discussion 530-2.

9. Villamaria CY, Eliason JL, Napolitano LM, Stansfield RB, Spencer JR, Rasmussen TE. Endovascular Skills for Trauma and Resuscitative Surgery (ESTARS) course: curriculum development, content validation, and program assessment. J Trauma Acute Care Surg 2014;76:929-35; discussion 935-6. 
10. Brenner M, Hoehn M, Pasley J, Dubose J, Stein D, Scalea T. Basic endovascular skills for trauma course: bridging the gap between endovascular techniques and the acute care surgeon. J Trauma Acute Care Surg 2014:77:286-91.

11. Qasim Z, Brenner M, Menaker J, Scalea T. Resuscitative endovascular balloon occlusion of the aorta. Resuscitation 2015;96:275-9.

12. Gamberini E, Coccolini F, Tamagnini
B, Martino C, Albarello V, Benni M, et al. Resuscitative endovascular balloon occlusion of the aorta in trauma: a systematic review of the literature. World J Emerg Surg 2017;12:42.

13. Morrison JJ, Galgon RE, Jansen JO, Cannon JW, Rasmussen TE, Eliason JL. A systematic review of the use of resuscitative endovascular balloon occlusion of the aorta in the management of hemorrhagic shock. J Trauma Acute
Care Surg 2016;80:324-34.

14. King DR. Initial care of the severely injured patient. N Engl J Med 2019:380: 763-70.

15. Ihm J, Choi H, Roh S. Flipped-learning course design and evaluation through student self-assessment in a predental science class. Korean J Med Educ 2017;29: 93-100. 